\title{
Mother-to-Child Transmission of HIV/AIDS during Pregnancy and Delivery and Associated Factors in the Region of Couffo in Benin
}

\author{
Jean Yaovi Daho1 ${ }^{*}$, Badirou Aguemon1, Pascal Hinnakou ${ }^{2}$ \\ ${ }^{1}$ Faculty of Health (FSS/UAC), Community Health and Epidemiology Unit, Cotonou, Benin \\ ${ }^{2}$ Information Center, Testing, Care and Research in Mono Department, Benin \\ Email: ‘jeanyaovi@yahoo.fr
}

How to cite this paper: Daho, J.Y., Aguemon, B. and Hinnakou, P. (2020) Mother-to-Child Transmission of HIV/AIDS during Pregnancy and Delivery and Associated Factors in the Region of Couffo in Benin. World Journal of AIDS, 10, 128-140. https://doi.org/10.4236/wja.2020.102011

Received: May 2, 2019

Accepted: June 25, 2020

Published: June 28, 2020

Copyright $\odot 2020$ by author(s) and Scientific Research Publishing Inc. This work is licensed under the Creative Commons Attribution International License (CC BY 4.0).

http://creativecommons.org/licenses/by/4.0/

\begin{abstract}
Evaluation of the effectiveness of the mother-to-child HIV Prevention Program, in Benin in 2016 reported a national rate of $6.7 \%$. The Region of Couffo, within 12 Regions (departments) in the country, had the highest rate of transmission, which was $16.1 \%$. The study aimed to determine transmission rate during pregnancy and delivery as well as the factors associated with it. This is a retrospective and analytical study based on a sample of seventy (70) babies born to HIV-infected mothers in 2016 in Couffo. Key findings showed, there is a perinatal transmission of five percent (5\%) and the factors associated with this transmission are: delay in carrying out first antenatal visits at the health facility, low frequency of visits performed versus number requested and appropriate time, poor health condition of mothers during pregnancy, absence or late start of antiretroviral care and treatment during pregnancy, irregular intake of intermittent presumptive treatment at sulfadoxine-pyrimethamine to prevent malaria, a short antiretroviral therapy (less than three months) for mothers before delivery and the default in cleaning mother's genital tract with betadine after the woman's water broke.
\end{abstract}

\section{Keywords}

HIV (Human Immunodeficiency Virus), Mother-to-Child Transmission, Pregnancy, Childbirth

\section{Introduction}

Aiming to eliminate new HIV infections among children and keep their mothers alive, UNAIDS has put in place a global action plan in which many countries in- 
cluding Benin, committed themselves to reduce mother-to-child transmission of HIV to less than five percent (5\%) [1].

A mid-term evaluation of the implementation of that plan in Benin in 2014 revealed a residual mother-to-child transmission rate of HIV at the national level of 7.62\% [2] and in 2016, at the end of implementation the rate was $6.70 \%$ [3]. At the departmental level, only the Couffo saw its transmission rate increase from $10.7 \%$ to $16.1 \%$ from 2014 to 2016 while the situation slowly improved in the other departments. To help understand the situation in Couffo, this study is initiated and is focused on HIV transmission during pregnancy and delivery. It aims to study the factors associated with this transmission. Specifically, it involves:

- the determination of the rate of HIV infection transmission from mother-to-child during pregnancy and delivery in the Couffo in 2016;

- the identification of the factors associated with this transmission in the Couffo in 2016.

\section{Study Framework and Method}

\subsection{Study Framework}

The study took place in Couffo, a department of $2404 \mathrm{Km}^{2}$ located in the South of Benin (West Africa) at that west side, Couffo, Benin shares borders with the Republic of Togo. It encompasses six (06) Districts (called Communes) which are Aplahoué, Djakotomey, Dogbo, Klouékanmè, Lalo and Toviklin. The department had in 2016 four (04) hospitals including two (02) from the private sector; forty-eight (48) health facilities; eleven (11) remote clinics (just for child delivery) and seven (07) other Remote clinics for care. Staff coverage rate in the region in 2016 is 0.11 doctor for ten thousand (10.000) inhabitants, 0.75 nurse for five thousand inhabitants and 0.81 midwives for five thousand women of reproductive age.

The HIV prevalence in Couffo is $2.2 \%$ versus $1.2 \%$ in Benin according to the DHS 2011-2012 [4]. Care and Treatment Centers are available in each District and while HIV Mother-to-Child prevention services are offered in in three (03) hospitals, 48 district health facilities and 11 remote clinics especially dedicated to child delivery.

\subsection{Study Type and Population}

This is a descriptive and analytical retrospective study of children born to HIV-infected mothers in 2016 in Couffo as well as their mothers. The study took place in September 2018.

The first target audience of this study is children born to HIV-infected mothers in 2016 in the Couffo department.

The secondary target audience is made of group of mothers of identified children, who delivered at the health facility and received care and treatment on those sites. 
The inclusion criteria are:

- For children: be born to a mother known to be HIV positive before or during pregnancy or childbirth during 2016 in the department of Couffo.

- For mothers: these are women who gave birth in Couffo in 2016 with a positive HIV status known before or in 2016.

- The exclusion criteria are:

- For children: not to have been born to an HIV-positive mother in 2016 in Couffo.

- For mothers: be HIV negative or be HIV positive but did not give birth in 2016 in Couffo.

\subsection{Sampling (Method and Technic)}

Non probabilistic method served for the selection of children and their mothers. The sampling was carried out for convenience from 78 children screened (tested) at the PCR in the first two months of life. Active search for these children within the community made it possible to find 70 of them. Key data on those children were collected (see Figure 1).

\subsection{Variables}

Dependent variable is infection of children to HIV. It is determined by virology using PCR with two methods: Positive PCR (HIV infected child) and negative PCR (child not infected).

The independent variables are, on the one hand, the maternal factors during pregnancy, which are socio-demographic characteristics, physical examination (number of antenatal visits carried out, prevention of malaria and anaemia), specific care and treatment (pregnant women having ARV and taking prophylactic CTM as well), biological check-up specific to HIV infection (CD4 assay), virological Tests (viral load, other biological tests to monitor tolerance to treatment.

Furthermore, they are related to child delivery conditions and identified variables are: duration of the ARV treatment before delivery, delivery mode, time

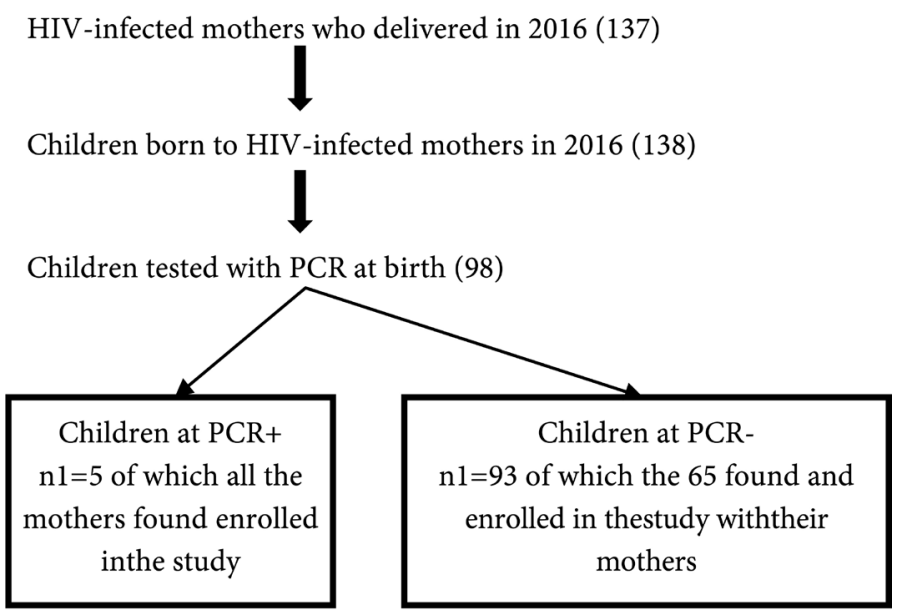

Figure 1. Method of selecting the children for the study. 
from fluids pocket break to child delivery and cleaning mother's genital tract with betadine after the woman's water broke.

\subsection{Data Collection}

Tools used for data collection are guidance for documents review, a questionnaire for an interview with HIV-positive mothers who delivered during the study period. It was done by Midwives as well as Nurses serving as Chiefs Managers of identified clinics/site and targeted all HIV-infected women who delivered in the department in 2016. Community Health workers, in this case, Mediators working at PMTCT sites who were trained and had expertise in giving continuous care and treatment to HIV-infected people, were called upon for the active research of the women concerned by the study. The pretest of the tools mentioned above was done during a pre-survey in Azovè city in the Commune of Aplahoué. Corrections were made before the actual survey started.

\subsection{Statistical Data Analysis}

Data were entered, corrected and then analyzed using SPSS Version 20.0 Software.

\subsection{Ethical Consideration}

The data recorded in the files of HIV-infected mothers at the PMTCT sites were analysed in strict discretion by Health staff involved in care and treatment to the identified mothers; those data were collected anonymously. The mother's participation in the study was voluntary and based on informed decision. The risk related to the survey was psychological and related to discussing HIV sero-positivity with women involved in the study. The main advantage to take from this study for communities is the need for them to set up a better organization to enable an effective medical follow-up (care and treatment) of HIV-infected persons.

\section{Findings}

\subsection{Description of the Study Targeted Population}

Almost two thirds (57.2\%) of the mothers surveyed had never been to school nor are they literate. Nine women out of ten were married with $47.1 \%$ who were in polygamous households. Among the women involved in the study, 5.7\% were pupils and students and more than one in five mothers (21.4\%) had at least four dependent children (Table 1).

\subsection{Mother-to-Child Transmission of HIV during Pregnancy and Delivery}

Of the 98 screened by PCR in the six weeks of life, five (05) were positive, i.e. a transmission of $5 \%$ 
Table 1. Socio-demographic characteristics of mothers.

\begin{tabular}{|c|c|c|}
\hline Socio-demographic characteristics & Number & Percentage \\
\hline \multicolumn{3}{|l|}{ Age (years old) } \\
\hline $19-25$ & 18 & 25.7 \\
\hline $26-35$ & 41 & 58.6 \\
\hline More than 35 & 11 & 15.7 \\
\hline \multicolumn{3}{|l|}{ Parity } \\
\hline 0 & 10 & 14.3 \\
\hline 1 & 13 & 18.6 \\
\hline 2 & 16 & 22.8 \\
\hline 3 & 13 & 18.6 \\
\hline More than 3 & 18 & 25.7 \\
\hline \multicolumn{3}{|l|}{ Educational level } \\
\hline Illiterate & 39 & 55.7 \\
\hline Literals & 1 & 1.5 \\
\hline Primary & 19 & 27.1 \\
\hline Secondary & 11 & 15.7 \\
\hline \multicolumn{3}{|l|}{ Marital status of mothers } \\
\hline Common-Law or monogamous married & 30 & 42.9 \\
\hline Common-Law or polygamous married & 33 & 47.1 \\
\hline Widow & 07 & 10 \\
\hline \multicolumn{3}{|l|}{ Mother religion } \\
\hline Unbeliever & 13 & 18.6 \\
\hline Endogenous religion & 18 & 25.7 \\
\hline Muslim & 3 & 4.3 \\
\hline Christian & 36 & 51.4 \\
\hline \multicolumn{3}{|l|}{ Mothers' profession } \\
\hline Pupil or student & 4 & 5.7 \\
\hline Housewife & 28 & 40.0 \\
\hline Farmer/craftswoman/artist & 17 & 24.3 \\
\hline Trader & 20 & 28.6 \\
\hline Civil servant & 1 & 1.4 \\
\hline \multicolumn{3}{|l|}{ Number of dependent children } \\
\hline 0 & 7 & 10.0 \\
\hline 1 & 13 & 18.6 \\
\hline 2 & 18 & 25.7 \\
\hline 3 & 17 & 24.3 \\
\hline More than 3 & 15 & 21.4 \\
\hline
\end{tabular}




\subsection{Factors Associated with the Transmission during Pregnancy}

\section{Socio-economic characteristics of mothers and perinatal transmission}

No socio-demographic characteristic of mother is significantly associated with transmission during pregnancy and delivery (Table 2).

\section{Maternal clinical factors and prenatal follow-up}

Risk of transmission appears with the delay in carrying out the first antenatal visit ( $1^{\text {st }}$ quarter). Also, carrying out at least four prenatal visits with qualified Health staff before delivery protects the child against HIV transmission. Children born to HIV-infected mothers, ranked by WHO (World Health Organization) at a clinical stage greater than one (1) are twice, more vulnerable to the the risk of HIV transmission (Table 3(a) and Table 3(b)).

Biological factors of the mother in antenatal and perinatal transmission

Few mothers have performed follow-up medical Tests (CD4, viral load, hemoglobins, etc). The association links between these factors and transmission could not be established.

Table 2. Socio-economic characteristics of mothers and perinatal transmission.

\begin{tabular}{|c|c|c|c|c|}
\hline & \multicolumn{3}{|c|}{ PCR } & \multirow{2}{*}{$\mathbf{P}$} \\
\hline & Positive & Negative & Total & \\
\hline \multicolumn{5}{|l|}{ Marital status of mothers } \\
\hline Common-Law or monogamous married & 3 & 27 & 30 & \multirow{3}{*}{0.168} \\
\hline Common-Law or polygamous married & 2 & 31 & 33 & \\
\hline Widow & 0 & 7 & 7 & \\
\hline \multicolumn{5}{|l|}{ Educational level } \\
\hline Illiterate & 3 & 36 & 39 & \multirow{4}{*}{0.231} \\
\hline Literale & 0 & 1 & 1 & \\
\hline Primary & 2 & 17 & 19 & \\
\hline Secondary & 0 & 11 & 11 & \\
\hline \multicolumn{5}{|l|}{ Family charge (Number of dependent children) } \\
\hline 0 & 1 & 6 & 7 & \multirow{5}{*}{0.366} \\
\hline 1 & 0 & 13 & 13 & \\
\hline 2 & 2 & 16 & 18 & \\
\hline 3 & 1 & 16 & 17 & \\
\hline More than 3 & 1 & 14 & 15 & \\
\hline \multicolumn{5}{|l|}{ Mothers' profession } \\
\hline Pupil or student & 0 & 4 & 4 & \multirow{5}{*}{0.299} \\
\hline Housewife & 2 & 26 & 28 & \\
\hline Farmer/craftswoman/artist & 2 & 15 & 17 & \\
\hline Trader & 1 & 19 & 20 & \\
\hline Civil servant & 0 & 1 & 1 & \\
\hline
\end{tabular}


Table 3. (a) Maternal clinical factors in prenatal and perinatal transmission; (b) Maternal clinical factors in prenatal and perinatal transmission.

(a)

\begin{tabular}{|c|c|c|c|c|}
\hline & \multicolumn{3}{|c|}{ PCR } & \multirow{2}{*}{$\mathbf{P}$} \\
\hline & Positive & Negative & Total & \\
\hline \multicolumn{5}{|c|}{ BMI during Pregnancy $\left(\mathrm{Kg} / \mathrm{m}^{2}\right)$} \\
\hline 18 to 25 & 2 & 46 & 48 & \multirow{3}{*}{0.294} \\
\hline 25.1 to 30 & 3 & 15 & 18 & \\
\hline 30 plus & 0 & 4 & 4 & \\
\hline \multicolumn{5}{|c|}{ E/C-1 Completion period } \\
\hline First trimester & 0 & 32 & 32 & \multirow{3}{*}{0.002} \\
\hline second trimester & 2 & 23 & 25 & \\
\hline Third trimester & 3 & 10 & 13 & \\
\hline \multicolumn{5}{|c|}{$\begin{array}{l}\text { Number of Antenatal Visitss performed } \\
\text { before delivery }\end{array}$} \\
\hline 0 & 0 & 1 & 1 & \multirow{5}{*}{0.011} \\
\hline 1 & 3 & 7 & 10 & \\
\hline 2 & 0 & 6 & 6 & \\
\hline 3 & 2 & 18 & 20 & \\
\hline More than 3 & 0 & 33 & 33 & \\
\hline
\end{tabular}

(b)

\begin{tabular}{|c|c|c|c|c|c|c|}
\hline \multirow{2}{*}{ WHO clinical stage } & \multicolumn{3}{|c|}{ PCR } & \multirow{2}{*}{ OR } & \multirow{2}{*}{ IC $95 \%$} & \multirow{2}{*}{$\mathbf{P}$} \\
\hline & Positve & Negative & Total & & & \\
\hline Good & 3 & 49 & 52 & 1 & & \\
\hline $\mathrm{Bad}$ & 2 & 16 & 18 & 0.490 & $0.075-3.197$ & 0.25 \\
\hline
\end{tabular}

Therapeutic factors of the mother in antenatal and perinatal transmission.

The absence or late start of ARV therapy during pregnancy increases the risk of transmission (Table 4(a) and Table 4(b)).

Compliance with antenatal prevention measures and perinatal transmission.

Irregular use of SP to prevent malaria exposes children three times more to contamination during pregnancy and childbirth (Table 5).

\section{Neonatal factors and perinatal transmission}

Duration of taking ARVs before delivering is correlated with perinatal transmission of HIV. The shorter this duration becomes, the higher the risk is. Furthermore, during delivery, default in cleaning the mother's genital tract with betadine after woman's water broke exposes children to HIV infection more than eleven times (Table 6(a) and Table 6(b)). 
Table 4. (a) Therapeutic factors of the mother in prenatal and perinatal transmission; (b) Therapeutic factors of the mother in antenatal and perinatal transmission.

(a)

\begin{tabular}{ccccc}
\hline & \multicolumn{3}{c}{ PCR } & P \\
\cline { 2 - 3 } & Positive & Negative & Total & \\
Put under ARV & 1 & 41 & 42 & 0.018 \\
First Quarter & 1 & 10 & 11 & \\
second Quarter & 2 & 9 & 11 & \\
Third Quarter & 1 & 5 & 6 & \\
No & & & & \\
Put under CTM & 2 & 49 & 51 & \\
second trimester & 2 & 8 & 10 & \\
Third trimester & 1 & 8 & 9 & \\
No & & & & \\
\hline
\end{tabular}

(b)

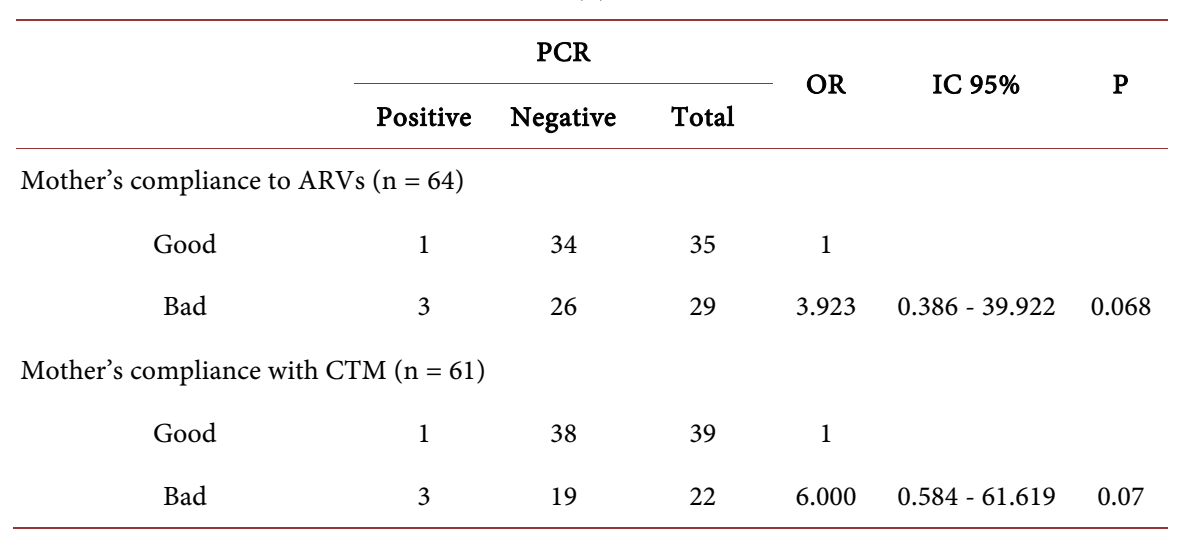

Table 5. Therapeutic factors of the mother in antenatal and perinatal transmission.

\begin{tabular}{|c|c|c|c|c|c|c|}
\hline & & PCR & & OR & IC $95 \%$ & $\mathbf{P}$ \\
\hline & Positive & Negative & Total & & & \\
\hline \multicolumn{7}{|l|}{ Prevention of anemia } \\
\hline Regular intake & 4 & 47 & 51 & 1 & & \multirow{2}{*}{0.424} \\
\hline Irregular intake & 1 & 18 & 19 & 1.533 & $0.160-14.646$ & \\
\hline \multicolumn{7}{|c|}{$\begin{array}{c}\text { Prevention of malaria Through the } \\
\text { use of MILLD }\end{array}$} \\
\hline Regular use of MILLD & 4 & 59 & 63 & 1 & & \multirow{2}{*}{0.272} \\
\hline Irregular use of MIILD & 1 & 6 & 7 & 0.407 & $0.039-4.251$ & \\
\hline \multicolumn{7}{|c|}{$\begin{array}{l}\text { Prevention of malaria by taking } \\
\text { Sulfadoxin-Pyrimethamin }\end{array}$} \\
\hline Correct SP intake & 3 & 54 & 57 & 1 & & \multirow{2}{*}{0.015} \\
\hline Incorrect SP intake & 2 & 11 & 13 & 0.306 & $0.046-2.049$ & \\
\hline
\end{tabular}


Table 6. (a) Neonatal factors and perinatal transmission; (b) Neonatal factors and perinatal transmission.

(a)

\begin{tabular}{ccccc}
\hline & \multicolumn{3}{c}{ PCR } & P \\
\cline { 2 - 3 } & Positive & Negative & Total & \\
\hline Taking of ARVs & 1 & 56 & 57 & \\
More than three months before delivery & 3 & 5 & 8 & 0.0002 \\
Less than three months before delivery & 1 & 4 & 5 & \\
No ARVs & 1 & & & \\
\hline
\end{tabular}

(b)

\begin{tabular}{|c|c|c|c|c|c|c|}
\hline & \multicolumn{3}{|c|}{ PCR } & \multirow{2}{*}{ OR } & \multirow{2}{*}{ IC 95\% } & \multirow{2}{*}{$\mathbf{P}$} \\
\hline & Positive & Negative & Total & & & \\
\hline \multicolumn{7}{|c|}{$\begin{array}{l}\text { Cleaning the woman genital } \\
\text { tract with betadine after rupture } \\
\text { of the water pocket }\end{array}$} \\
\hline Yes & 3 & 63 & 66 & 1 & & \multirow{2}{*}{0.000} \\
\hline No & 2 & 2 & 4 & 0.048 & $0.005-0.472$ & \\
\hline \multicolumn{7}{|l|}{ Children mode } \\
\hline Normal childbirth & 5 & 53 & 58 & 1 & & \multirow[b]{2}{*}{0.149} \\
\hline $\begin{array}{c}\text { Cessarean status during } \\
\text { pregnancy }\end{array}$ & 0 & 12 & 12 & 0.914 & $0.844-0.989$ & \\
\hline \multicolumn{7}{|l|}{$\begin{array}{l}\text { Nutitional status during } \\
\text { pregnancy }\end{array}$} \\
\hline Good & 2 & 32 & 34 & 1 & & \multirow[b]{2}{*}{0.149} \\
\hline $\mathrm{Bad}$ & 3 & 33 & 36 & 0.688 & $0.108-4.390$ & \\
\hline
\end{tabular}

\section{Discussion}

The main findings constituting the limits of this study are:

- the difficulties in finding the few children born in several of the peripheral sites maintained by nurses, which did not allow an optimal appreciation of the real-time operation of these sites in the system of supply of childcare services PMTCT in the department;

- failure to fill in the supports (maternal cards, follow-up files, follow-up registers for HIV-positive mothers and exposed children), which resulted in the recording of several missing data for several variables;

- lack of biological monitoring. Although most of the children found come from care sites, which are thought to be more structured and able to offer the service package in accordance with standards and procedures, few women have benefited from CD4 counting and almost none have benefited from the viral load assay. This did not allow us to assess the immunological and virological states of the mothers in prenatal, childbirth. 


\subsection{Mother-to-Child Transmission of HIV during Pregnancy and Delivery}

Mother to child HIV transmission during pregnancy and delivery in the Couffo found in this study is $5 \%$. This rate is higher than that expected in the national elimination plan where it should be below 2\% [5] Identifying the factors associated with this high transmission and managing them earlier will enable the department of Couffo to align with the elimination objective rate, intended in the country.

\subsection{Socio Demographic Characteristics}

Almost two thirds (57.2\%) of the mothers involved in this study have never been to school and are not literate. This is a critical problem in the Department of Couffo where according to the fourth general census of population and housing (RGPH4), girls' education is still a problem: $62.6 \%$ of net School enrolment rate of girls in 2013 against $69.6 \%$ for boys [6].

Within the mothers of children considered in the study, 5.7\% were pupils or students, this raises the problem of early marriage in Benin where, according to the EDS VI (DHS VI) in Benin, 11\% of young adolescents (girls and boys) were already married at 15 years old and $32 \%$ of them were already married at 18 [4]. Furthermore, this observation highlights the problem of pregnancies in schools. Indeed, according to statistics published by the Ministry of Secondary Education of Benin in January 2018, 2763 student girls became pregnant during the 2016-2017 school years. Already in 2013 the UN Committee on the elimination of discrimination against women was concerned with the "high level of illiteracy rates, the low rate of school completion and the high level of dropout which are notably due to the large number of early pregnancies and early or forced marriages" in Benin [7]. A study carried out by the ICRW and the UNICEF on "child marriages, early pregnancies and family formation in West and Central Africa" has moreover shown that: out of 15 countries where the rate of child marriages exceeds 30\%, nine are located in West and Central Africa, ...., the region also has the highest rate of early childbirth in the world. These trends are compounded by high rates of poverty and dropout among adolescents (especially girls) as well as low use of reproductive health services [8]. The problem of the insufficient supply of sexual and reproductive health services for adolescents and young people is thus raised in our countries.

The mothers were mostly housewives (40\%) farmers $(24.3 \%)$ or traders of sundries (28.6\%) and the average number of dependent children per mother is ( 0 to 7 ). This is not negligible given income level. This situation makes them vulnerable to, among other things, HIV infection because they are highly dependent or subject to the will of their spouses. The management of HIV information by the infected mother at home, blow in an environment where stigma and discrimination are rampant.

In addition, nine out of ten women were married with more than half of them 
who were in polygamous households. This situation is a main characteristic of the department of Couffo where polygamy is mostly widespread according to the EDS IV (55\%) among women and $40 \%$ among men). This raises the problem of the exposure of spouses and Co-wives to HIV infection, all the more since sharing of HIV status is not common within families. This could be one of the explanations for the high prevalence of HIV infection in Couffo (2,2\% according to the EDSIV) compared to the national average (1.2\% according to the EDSIV) and compared to the country's departments.

\subsection{Factors Associated with HIV Transmission during Pregnancy and Breastfeeding in the Couffo}

\section{Socio-demographic factors}

No sociological and economic factor is significantly associated with HIV mother-to-child transmission during pregnancy and delivery. However, the study carried out in Benin in 2011 showed that at the national level, the risk of global transmission was higher in children born to single mothers and assimilated (Widows and divorcees) than that of children born to monogamous married mothers [9]. Other further research may provide more guidance on these factors. All of the infected children found in this study were born to illiterate or primary school mothers. We could assume that the more educated the mother, the more she integrates prevention advice and measures.

\section{Maternal factors and perinatal clinical monitoring.}

Poor physical health of mothers during the prenatal period is associated with the transmission of HIV from mother to child during pregnancy and delivery in the Couffo. What is found through several studies both in Benin and internationally and the factors identified were the low weight index [10], poor general condition [11] [12] [13]. The delay in carrying out antenatal visits as well as their low frequency is associated with the transmission of HIV during pregnancy and delivery. Performing at least four antenatal visits before delivery protects the child against contamination. This shows the need to strengthen awareness for regular medical follow-up of pregnancies in the healthcare setting. Besides, WHO recommends that pregnant women have at least eight contacts with health services before delivery, though its new antenatal care guidelines adopted in November 2016.

\section{Biological factors of mothers in prenatal}

Lack of regular and appropriate checks-up performed by mothers involved in this study from pregnancy to delivery justifies that it was not possible to assess the effect of biological factors on HIV transmission from mother-to the child in Couffo.

\section{Therapeutic factors of mothers in prenatal}

The maternal therapeutic factors found during the prenatal period associated with the HIV transmission to the child in the Couffo are the absence and/or the late start of ARV treatment during pregnancy. The results are similar to those 
observed already in 2011 at the national level in Benin where it appeared that children whose mothers had not received any PMTCT commodity for prophylaxis, had a much higher risk (8 times) compared to children whose mothers had triple therapy [9]. Likewise, in 2014, it was proved that triple therapy or tri prophylaxis in the mother started early was a guarantee on the non-transmission of HIV to the child [10]. In 2016, the moment of starting of ARV was also one of the factors associated with transmission [3]. These data can sufficiently demonstrate the value of a triple therapy which, started early in the mother, contributes to reduce the risk of transmission. This is due to sufficient exposure to antiretroviral which results in suppression of the viral load.

Irregular intake of intermittent presumptive sulfadoxine-pyrimethamine therapy to prevent malaria exposes three times more children to contamination during pregnancy and childbirth. This raises the problem of the interaction between malaria and HIV infection. According to WHO, although there is evidence that HIV increases the risk of malaria infection and clinical malaria in adults, more research is needed to study the impact of malaria on the natural process of HIV [13]. The present results may be indicative for this purpose.

\subsection{Neonatal Factors}

Children whose mothers took antiretroviral for less than three months before delivery i present a high risk (more than 20 times) of HIV transmission from their mother compared to those cases in where mothers took ARVs for more than three months before delivery. This would be related to the duration of the exposure of mothers to ARVs which leads to the suppression of the viral load in them before delivery. Moreover, during delivery, the default in cleaning mother's genital tract with "betadine" after mother's water broke, increases (11 times) the risk of HIV transmission to children. This reinforces application of this measure which is included in the package called "clean and safe delivery" and which is included in the protocol for preventing mothers-to-child transmission.

\section{Conclusion}

This study highlights the importance of correct prenatal follow-up in the healthcare setting. It helps provide HIV-pregnant women with appropriate and different relevant advice and measures as recommended by the national PMTCT protocol, as well as facilitate good compliance to different therapies (ARV, intermittent presumptive treatment of malaria, prophylaxis with CTM). Non-compliance with those factors is associated with HIV transmission during pregnancy and breastfeeding in the Couffo.

\section{Conflicts of Interest}

The authors declare no conflicts of interest regarding the publication of this paper. 


\section{References}

[1] Ministry of Health (2012) National Plan to Eliminate Mother-to-Child Transmission of HIV (2012-2015). Benin.

[2] Ministry of Health (2015) Evaluation of Mother-to-Child Transmission of HIV in Benin.

[3] Ministry of Health (2017) Evaluation of Mother-to-Child Transmission of HIV in Benin.

[4] Republic of Benin (2012) Fourth Demographic and Health Survey.

[5] Ministry of Health (2016) National Plan to Eliminate Mother-to-Child Transmission of HIV (2016-2020). Benin.

[6] Republic of Benin, INSAE (2013) Four General Censuses of Population and Housing.

[7] French Republic, DIDR-OFPRA Benin (2017) Forced Marriages.

[8] UNICEF. ICRW Child Marriage, Early Pregnancy and Family Formation in West and Central Africa.

[9] Ministry of Health (2013) Evaluation of Mother-to-Child Transmission of HIV in Benin from 2008 to 2009. Final Report, Benin.

[10] Ministry of Health (2015) Evaluation of Mother-to-Child Transmission of HIV in Benin.

[11] Lallemant, M., Le Coeur, S., Samba, L., Cheynier, D., M’Pélé, P. and Nzingoula, S. (1994) Congolese Research Group of Mother to Child Transmission of VIH. Mother to Child Transmission of HIV 1 in Congo, Central Africa. Aids, 8, 1451-1456. https://doi.org/10.1097/00002030-199410000-00012

[12] Tess, B.H., Rodrigues, L.C., Newell, M.-L., Dunn, D.T., Lago, T.D.G. and the Sao Paulo Collaborative Study for Vertical Transmission of HIV-1 (1998) Breastfeeding, Genetic, Obstetric and Other Risk Factors Associated with Mother-to-Child Transmission of HIV-1 in Sao Paulo State, Brazil. Aids, 12, 513-520.

https://doi.org/10.1097/00002030-199805000-00013

[13] https://www.who.int/malaria/areas/high risk groups/hiv aids patients/en 